OPEN ACCESS

Edited by:

R. Keith Reeves,

Duke University, United States

Reviewed by:

Marina Tuyishime,

Duke University, United States

Justin Pollara,

Duke University, United States

Hans Klingemann,

NantKwest, Inc., United States

${ }^{*}$ Correspondence:

Bruce Walcheck

walch003@umn.edu

Jianming Wu

jmwu@umn.edu

Specialty section:

This article was submitted to

Comparative Immunology,

a section of the journal

Frontiers in Immunology

Received: 22 December 2021

Accepted: 31 January 2022

Published: 24 February 2022

Citation:

Hullsiek R, Li Y, Snyder KM, Wang S, Di D, Borgatti A, Lee C,

Moore PF, Zhu C, Fattori $C$,

Modiano JF, Wu J and Walcheck B (2022) Examination of lgG FC Receptor

CD16A and CD64 Expression by

Canine Leukocytes and Their ADCC Activity in Engineered NK Cells.

Front. Immunol. 13:841859. doi: 10.3389/fimmu.2022.841859

\section{Examination of IgG Fc Receptor CD16A and CD64 Expression by Canine Leukocytes and Their ADCC Activity in Engineered NK Cells}

\author{
Robert Hullsiek ${ }^{1}$, Yunfang $L_{i}{ }^{1}$, Kristin M. Snyder ${ }^{1,2}$, Sam Wang ${ }^{1}, D a D i^{1}$, \\ Antonella Borgatti ${ }^{2,3,4,5,6}$, Chae Lee ${ }^{1}$, Peter F. Moore ${ }^{7}$, Cong Zhu ${ }^{1}$, Chiara Fattori ${ }^{3,4}$, \\ Jaime F. Modiano ${ }^{2,3,4,5,8,9,10}$, Jianming $W_{u^{1,2,4 *}}$ and Bruce Walcheck ${ }^{1,2,4,5,8 *}$
}

${ }^{1}$ Department of Veterinary and Biomedical Sciences, University of Minnesota, St. Paul, MN, United States, ${ }^{2}$ Animal Cancer Care and Research Program, University of Minnesota, St. Paul, MN, United States, ${ }^{3}$ Department of Veterinary Clinical Sciences, College of Veterinary Medicine, University of Minnesota, St. Paul, MN, United States, ${ }^{4}$ Masonic Cancer Center, University of Minnesota, Minneapolis, MN, United States, ${ }^{5}$ Center for Immunology, University of Minnesota, Minneapolis, MN, United States, ${ }^{6}$ Clinical Investigation Center, University of Minnesota, St. Paul, MN, United States, ${ }^{7}$ Department of Pathology, Microbiology, Immunology, School of Veterinary Medicine, University of California, Davis, CA, United States, ${ }^{8}$ Stem Cell Institute, University of Minnesota, Minneapolis, MN, United States, 9 Institute for Engineering in Medicine, University of Minnesota, Minneapolis, MN, United States, ${ }^{10}$ Department of Laboratory Medicine and Pathology, School of Medicine, University of Minnesota, Minneapolis, MN, United States

Human natural killer (NK) cells can target tumor cells in an antigen-specific manner by the recognition of cell bound antibodies. This process induces antibody-dependent cellmediated cytotoxicity (ADCC) and is exclusively mediated by the low affinity lgG FC receptor CD16A (FCyRIIIA). Exploiting ADCC by NK cells is a major area of emphasis for advancing cancer immunotherapies. CD64 (FcyRl) is the only high affinity lgG FCR and it binds to the same IgG isotypes as CD16A, but it is not expressed by human NK cells. We have generated engineered human NK cells expressing recombinant CD64 with the goal of increasing their ADCC potency. Preclinical testing of this approach is essential for establishing efficacy and safety of the engineered NK cells. The dog provides particular advantages as a model, which includes spontaneous development of cancer in the setting of an intact and outbred immune system. To advance this immunotherapy model, we cloned canine CD16A and CD64 and generated specific mAbs. We report here for the first time the expression patterns of these FcyRs on dog peripheral blood leukocytes. CD64 was expressed by neutrophils and monocytes, but not lymphocytes, while canine CD16A was expressed at high levels by a subset of monocytes and lymphocytes. These expression patterns are similar to that of human leukocytes. Based on phenotypic characteristics, the CD16A $A^{+}$lymphocytes consisted of T cells $\left(C D 3^{+} C D 8^{+} C D 5^{\text {dim }} \alpha / \beta\right.$ $\left.\mathrm{TCR}^{+}\right)$and NK cells $\left(\mathrm{CD}^{-} \mathrm{CD}^{-} \mathrm{CD}^{-} 4^{+}\right.$), but not B cells. Interestingly, the majority of canine $\mathrm{CD}_{16 \mathrm{~A}^{+}}$lymphocytes were from the $T$ cell population. Like human CD16A, canine CD16A was downregulated by a disintegrin and metalloproteinase 17 (ADAM17) upon leukocyte activation, revealing a conserved means of regulation. We also directly 
demonstrate that both canine CD16A and CD64 can induce ADCC when expressed in the NK cell line NK-92. These findings pave the way to engineering canine NK cells or T cells with high affinity recombinant canine CD64 to maximize ADCC and to test their safety and efficacy to benefit both humans and dogs.

Keywords: natural killer cells (NK cells), Fc receptor, IgG, canine (dog), antibody-dependent cell-mediated cytotoxicity (ADCC)

\section{INTRODUCTION}

NK cells are innate cytotoxic lymphocytes that interrogate cells in the body to identify those that are stressed, infected, or neoplastic (1). NK cells are rapidly activated and release cytolytic factors as well as cytokines and chemokines that stimulate other components of the immune system. NK cell activation is mediated by various ligands and by antibodies attached to target cells (1). The latter process induces an effector function referred to as antibodydependent cell-mediated cytotoxicity (ADCC) and it is exclusively mediated by the IgG Fc receptor CD16A (Fc $\gamma$ RIIIA) on human NK cells $(2,3)$.

Anti-tumor mAbs provide a rapidly expanding repertoire of antigen-specific targeting elements for NK cells (4). However, their clinical performance is limited by certain attributes of CD16A. It is well described that CD16A undergoes rapid ectodomain shedding by a disintegrin and metalloproteinase 17 (ADAM17) upon NK cell activation with diverse stimuli (3). Preventing this process in human NK cells by engineering a noncleavable CD16A or blocking ADAM17 enhanced their release of IFN $\gamma$ and target cell killing in the presence of $\mathrm{mAb}$ therapies (5-7). CD16A is also a low affinity Fc $\gamma \mathrm{R}$ that stably binds to cell-bound IgG, but not soluble monomeric IgG. In humans, two CD16A allelic variants with either a phenylalanine (F) or a valine $(\mathrm{V})$ at amino acid position 158 have been described (8). CD16A-158V has $\approx 2$-fold higher affinity for IgG1 as compared to CD16A-158F $(9,10)$. Studies have shown that cancer patients homozygous for CD16A-158V responded significantly better to tumor targeting mAbs (11-13), indicating that increased binding affinity between CD16A and tumortargeting $\mathrm{mAbs}$ will enhance NK cell anti-tumor effector functions. A strategy to increase both the binding affinity and avidity between NK cells and antibody-opsonized tumor cells has involved modifying the Fc $\gamma \mathrm{R}$ on NK cells $(3,14,15)$. Human CD64 (Fc $\gamma R I)$, the only high affinity IgG Fc receptor, binds to the same IgG isotypes as CD16A but with > 30-fold higher affinity than CD16A-158V $(10,16)$. CD64, however, is expressed by myeloid leukocyte populations but not lymphocytes, including NK cells (10). Therefore, we have engineered human NK cells to express recombinant versions of CD64 to increase their attachment efficiency to antibody-coated tumor cells to kill these cells $(17,18)$. Moreover, due to its high affinity state, NK cells expressing recombinant CD64 can be "armed" with antitumor mAbs, which can be switched for universal tumor antigen targeting $(14,17,18)$.

The clinical translation of engineered NK cell immunotherapies into successful cancer therapies has been slow, due in part to the use of animal models with critical species differences in their immune cell effector functions. For instance, the study of ADCC in mice is confounded by the considerable divergence in human and mouse Fc $\gamma \mathrm{R}$ expression profiles and function. Mature human NK cells uniformly express high levels of CD16A under steady state conditions. Mouse leukocytes express two versions of CD16 (10). Mouse CD16 (FcrRIII) is expressed at low levels by NK cells and is actually more closely related to human CD32A (FcyRIIA), which is not expressed by human NK cells $(10,19)$. CD16-2 (FcyRIV) is the mouse orthologue of CD16A, but it is not expressed by resting NK cells (20). In addition, CD16-2 has been reported to bind IgE and promote IgE-mediated inflammation $(21,22)$. Both versions of mouse CD16 are also not shed by ADAM17 (23), demonstrating differences in their regulation compared to human CD16A. An ideal animal model for understanding the mechanisms that underlie success and failure of human immunotherapies should incorporate heterogeneous spontaneous disease and an intact immune system that is similar to humans. A comparable incidence of human and certain canine malignancies, combined with their shared biologic and pathologic characteristics, and similar response to therapy indicate that dogs can provide a clinically relevant disease model (24-26).

Based on morphology, canine NK cells are medium to large lymphocytes with electron-dense intracytoplasmic granules that contain granzyme B and perforin. These cells express at the mRNA level several genes associated with NK cells, such as NK1.1, NKG2D, CD94, CD96, NKp30, NKp44, NKp46, NKG2D, CD16A, DNAM-1, perforin, and granzyme B (26, 27 ), and based on transcriptome analysis, canine NK cells are globally more similar to human NK cells than to mouse NK cells (26). Canine NK cells also mediate natural cytotoxicity and ADCC (27-32). However, a lack of available species-specific antibodies has hindered efforts to study Fc $\gamma$ Rs on canine leukocytes. The focus of our study was to characterize canine CD16A and CD64 leukocyte expression patterns and their capacity to induce ADCC.

\section{MATERIALS AND METHODS}

\section{Cells}

Peripheral blood was collected from healthy pet dogs with consent from owners. The dogs consisted of various breeds and mixed breeds. All animals had received routine veterinary care, vaccinations, parasite control, and were considered to be in overall good health. Blood collection was carried out in strict accordance with the recommendations in the Guide for the Care 
and Use of Laboratory Animals of the National Institutes of Health. The protocol was approved by the Institutional Animal Care and Use Committee of the University of Minnesota (Protocol Numbers: 1304-30546A and 1903-36913A). Blood was collected in K2-EDTA blood collection tubes (BD Biosciences, Franklin Lakes, NJ). Total leukocytes and PBMCs were isolated as we have previously described (33). Leukocytes with $\geq 95 \%$ viability, as assessed by trypan blue staining, were used in the described assays. Cell lines used were NK-92MI cells, an IL-2 independent version of NK-92 cells (34), SKOV-3 cells, and 293T, which were obtained from ATCC (Manassas, VA). FreeStyle 293-F cells were obtained from Thermo Fisher Scientific (Waltham, MA). All cells were cultured per the manufacturer's directions, as we have previously described (17, 18). For cell activation, leukocytes were stimulated with phorbol12-myristate-13-acetate (PMA) (MilliporeSigma, Burlington, MA), as previously described (33). Some cells were preincubated for $30 \mathrm{~min}$ on ice with the function-blocking antADAM17 mAb MEDI3622 $(5 \mu \mathrm{g} / \mathrm{ml})$ prior to activation.

\section{Antibodies}

To produce mAbs to canine CD16A and CD64, BALB/c mice were immunized intraperitoneally with purified soluble protein of each Fc $\gamma \mathrm{R}$ and hybridomas generated based on previous methods $(35,36)$. The anti-ADAM17 mAb MEDI3622 has been previously described $(5,33,37)$. The anti-canine $\alpha / \beta$ TCR and $\gamma / \delta$ TCR mAbs (CA15.8G7 and CA20.8H1, respectively) have been previously described $(30,38,39)$. Isotype-matched negative control mAbs were purchased from BioLegend (San Diego, CA) and BD Biosciences (Franklin Lakes, NJ). Affinity purified canine serum IgG was purchased from Southern Biotech (Birmingham, AL). Fluorophore or biotin-conjugated $\mathrm{F}\left(\mathrm{ab}^{\prime}\right)_{2}$ goat anti-mouse secondary antibodies and fluorophoreconjugated streptavidin were purchased from Jackson ImmunoResearch Laboratories (West Grove, PA) and BioLegend. Zombie Violet ${ }^{\mathrm{TM}}$ Fixable Viability Kit was purchased from Biolegend. All commercially available mAbs are listed in Table $\mathbf{1 .}$

\section{Flow Cytometry}

For cell staining, nonspecific antibody binding sites were blocked for 30 min using 25\% canine serum and 25\% FBS in PBS buffer (without $\mathrm{Ca}^{+2}$ and $\mathrm{Mg}^{+2}$ ) (Lonza, Walkersville, $\mathrm{MD}$ ) prior to their staining with antibodies. All cell staining was analyzed on a
FACSCelesta instruments (BD Biosciences), as previously described (33). Briefly, for controls, fluorescence minus one was used as well as appropriate isotype-matched antibodies. An FSC-A/SSC-A plot was used to set an electronic gate on leukocyte populations and an FSC-A/FSC-H plot was used to set an electronic gate on single cells. Fixable viability dyes eFluor 506 (Thermo Fisher Scientific) or Zombie Violet (BioLegend, San Diego, CA) were used to assess live vs. dead cells, as per the manufacturer's instructions. Canine leukocyte subsets were identified based on their forward and side light-scattering characteristics and various phenotypic markers, as described. In some cases, we attempted to enhance the staining by particular mAbs to better distinguish leukocyte subsets, as was the case for the anti-CD94 mAb HP-3D9. This was done by staining dog cells leukocytes with an unconjugated $\mathrm{mAb}$, biotinconjugated $\mathrm{F}\left(\mathrm{ab}^{\prime}\right)_{2}$ goat anti-mouse secondary antibodies, then fluorophore-conjugated streptavidin. Cell washes were performed between all steps. If the cells were to be stained with additional mouse-derived mAbs, the cells were first treated for $15 \mathrm{~min}$ with $5 \%$ mouse serum in PBS buffer. This served to occupy any free arms of cell-attached anti-mouse secondary antibodies, preventing them from binding subsequently added mouse-derived mAbs, which would result in artifactual staining.

Canine IgG adsorption to NK-92 cells was performed as previously described $(17,18)$, with some modifications. Briefly, cells were incubated with the indicated concentrations of canine IgG previously biotinylated using an EZ-Link ${ }^{\mathrm{TM}}$ Sulfo-NHS-LCBiotin Kit (Thermo Fisher Scientific) per the manufacturer's instructions, for $2 \mathrm{~h}$ at $37^{\circ} \mathrm{C}$ in MEM- $\alpha$ basal media supplemented with HEPES (10 mM), and 2-mercaptoethanol $(0.1 \mathrm{mM})$. Binding levels of biotinylated canine IgG was determined by staining the cells with allophycocyaninstreptavidin (Jackson ImmunoResearch).

\section{Western Blotting}

Protein concentrations were quantified using a bicinchoninic acid assay (BCA) (Pierce Biotechnology, Waltham, MA). Five micrograms of protein [1X Laemmli sample buffer (Bio-Rad Laboratories), 0.1M DTT] was resolved by SDS-PAGE and transferred to a nitrocellulose membrane. Blots were blocked in Intercept TBS blocking buffer (LI-COR Biosciences, Lincoln, $\mathrm{NE}$ ) for $1 \mathrm{~h}$ at room temperature and incubated with primary antibodies and Quick Western IRDye 680RD detection reagent

TABLE 1 | Commercially available mAbs.

\begin{tabular}{|c|c|c|c|}
\hline Antigen & Clone & Species & Company \\
\hline Influenza Hemagglutinin A-Tag & 12CA5 & Mouse & Santa Cruz Biotechnology, Dallas, TX \\
\hline canine CD4 & YKIX302.9 & Rat & Bio-Rad Laboratories, Hercules, CA \\
\hline canine CD3 & CA17.2A12 & Mouse & Bio-Rad Laboratories \\
\hline canine CD5 & YKIX322.3 & Rat & Bio-Rad Laboratories \\
\hline human CD14 & TÜK4 & Mouse & Bio-Rad Laboratories \\
\hline canine CD20 & $6 C 12$ & Caninized & Invivogen, San Diego, CA \\
\hline canine CD20 & $6 \mathrm{C} 12$ & Mouse & Invivogen \\
\hline canine NKp46 & $48 \mathrm{~A}$ & Mouse & MilliporeSigma, Burlington, MA \\
\hline human CD94 & HP-3D9 & Mouse & BD Biosciences, Franklin Lakes, NJ \\
\hline
\end{tabular}


(LI-COR Biosciences) overnight at $4^{\circ} \mathrm{C}$. Blots were visualized using an Odyssey imager (LI-COR Biosciences). Primary antibodies used were anti-canine CD64 clone 10 and anticanine-CD16A clone $4 \mathrm{~A} 5$ at $5 \mu \mathrm{g} / \mathrm{ml}$ each.

\section{Cytotoxicity Assays}

ADCC assays were conducted using a DELFIA EuTDA cytotoxicity according to the manufacturer's instructions (PerkinElmer, Waltham, MA) and as we have previously described $(17,18)$. Briefly, SKOV-3-canine CD20 target cells were labeled with Bis(acetoxymethyl)-2-2:6,2 terpyridine 6,6 dicarboxylate (BATDA) for $30 \mathrm{~min}$ in their culture medium, washed in culture medium, and pipetted into a 96-well nontissue culture-treated U-bottom plates at a density of $8 \times$ $10^{3}$ cells/well. Caninized anti-canine CD20 mAb was either adsorbed to NK-92 cells at $5 \mu \mathrm{g} / \mathrm{ml}$ in MEM- $\alpha$ basal media supplemented with HEPES (10 mM) then washed with MEM- $\alpha$ basal media or the mAb was added directly to the SKOV-3 cells at $5 \mu \mathrm{g} / \mathrm{ml}$ and NK-92 cells were added at the indicated E:T ratios. The plates were centrifuged at $400 \times \mathrm{g}$ for $1 \mathrm{~min}$ and then incubated for $2 \mathrm{~h}$ in a humidified $5 \% \mathrm{CO}_{2}$ atmosphere at $37^{\circ} \mathrm{C}$. At the end of the incubation, the plates were centrifuged at $500 \times \mathrm{g}$ for $5 \mathrm{~min}$ and supernatants were transferred to a 96 well DELFIA Yellow Plate (PerkinElmer) and combined with europium. Fluorescence was measured by time-resolved fluorometry using a BMG Labtech CLARIOstar plate reader (Cary, NC). BATDAlabeled target cells alone with or without therapeutic antibodies were cultured in parallel to assess spontaneous lysis and in the presence of $1 \%$ Triton-X to measure maximum lysis. ADCC for each sample is represented as \% specific release and was calculated using the following formula: Percent Specific Release $=($ Experimental release - Spontaneous release $) /($ Maximal release - Spontaneous release ${ }^{\star} 100$. For each experiment, assays were conducted in triplicate that were measured using two or three replicate assay wells.

\section{Cloning of Canine CD16A, CD64, and CD20, Generation of Expression Constructs, and Cell Line Transduction}

Total RNA was isolated from canine peripheral blood leukocytes using TRIzol total RNA isolation reagent (Thermo Fisher Scientific). Peripheral blood cDNA was synthesized with the SuperScript First-Strand Synthesis (Thermo Fisher Scientific) and used in RT-PCR for expression construct generation. Fulllength canine CD16A cDNA corresponding to two extracellular domains, transmembrane segment, and cytoplasmic region was amplified using the forward primer 5'-CTC TAG ACT GCC GGA TCC GCA GTG ACT TGC TGA CCC TAA TGT G-3' and the reverse primer 5'-TCG AAT TTA AAT GGA TCC AGA GAG GTC CAG AGG GGT TGC TTT -3'. The underlined nucleotides indicate Bam $\mathrm{HI}$ restriction sites. To generate $\mathrm{N}$ terminus hemagglutinin A (HA)-tagged canine CD16A, we amplified a cDNA fragment using the forward primer (5'-GCC CAG CCG GCC AGA TCT ACA CAA GCT GCA GAT GTC CCA-3') and the reverse primer (5'- GCG GAT CCC GGG AGA TCT AGA GAG GTC CAG AGG GGT TGC TTT -3’).
The underlined nucleotides indicate Bgl II restriction sites. An In-Fusion HD Cloning Kit (Takara Bio USA, San Jose, CA) was used to clone the canine CD16A cDNA fragment into a pDisplay vector (Thermo Fisher Scientific) linearized with Bgl II (New England Biolabs, Ipswich, MA). The expression cassette consisting of Igא signal peptide, $\mathrm{N}$-terminal HA tag, and canine CD16A was amplified using the forward primer (5'TCT AGA CTG CCG GAT CCA CTA GTA ACG GCC GCC AGT GT-3') and the reverse primer (5'- TCG AAT TTA AAT GGA TCC AGA GAG GTC CAG AGG GGT TGC TTT-3'). The underlined nucleotides indicate $\mathrm{Bam}$ HI restriction sites. Canine CD16A or HA-tagged CD16A were then cloned into the retrovirus expression vector pBMN-I-GFP (Addgene, Watertown, MA) linearized by Bam HI (New England Biolabs) using the In-Fusion HD Cloning Kit.

Full-length canine CD64 cDNA corresponding to three extracellular domains, transmembrane segment, and cytoplasmic region was amplified using the forward primer (5'TCT AGA CTG CCG GAT CCG GAG ATA ACA TGT GGC TCT TGA CAG TTC TA -3') and the reverse primer (5'- TCG AAT TTA AAT GGA TCC AAA AAG AAG TGG GAG GCA CCA TC-3'). The underlined nucleotides indicate Bam HI restriction sites. HA-tagged canine $\mathrm{CD} 64$ was amplified using the forward primer (5'-GCC CAG CCG GCC AGA TCT CAA ACA GAC CCC GTA AAG GCA -3') and the reverse primer (5'GCG GAT CCC GGG AGA TCT AAA AAG AAG TGG GAG GCA CCA TC -3'). The underlined nucleotides indicate $B g l$ II restriction sites. Their cloning into pDisplay and/or pBMN-IGFP were carried out as described above.

Full-length canine CD20 cDNA was amplified using the forward primer (5'-TCT AGA CTG CCG GAT CCA GAG GGT GAG ATG ACA ACA CCC AGA-3') and the reverse primer (5'-TCG AAT TTA AAT GGA TCC TTA AGG GAT GCT GTC GTT TTC TAT-3'). The underlined nucleotides indicate Bam HI restriction sites. The cloning of canine CD20 into pBMN-I-GFP was carried out as described above. The expression of all constructs in pBMN-I-GFP were confirmed using the sequencing primers 5'-TAG CTG GAA GAA CAC GCC CGT A-3' and 5'-GCA GAA GTA GGA GCC ATT GTG T-3'. Pseudo retrovirus particles were generated as previously described (40), and were subsequently used for NK-92 or SKOV3 cell transduction. Cells were sorted through FACSAria II cell sorting on GFP expression (BD Biosciences).

\section{Cloning of Soluble Canine CD16A and CD64, Generation of Expression Constructs, and Cell Line Transduction}

Canine CD16A cDNA corresponding to amino acids 1-205 with a $6 \times$ histidine-tag at the carboxyl terminus was amplified using the forward primer 5'-GAA GAC ACC GAC TCT AGA GCA GTG ACT TGC TGA CCC TAA TGT GA -3' (the underlined nucleotides indicate an $X b a$ I restriction site) and the reverse primer 5'-GTA GTC AGC CCG GGA TCC TTA ATG ATG ATG ATG ATG ATG GGG CCA GTG TGA AAG GAG TA-3' (the underlined nucleotides indicate a Bam HI restriction site). Canine CD64 cDNA corresponding to amino acids 1-280 with a 
$6 \times$ histidine-tag at the carboxyl terminus was amplified using the forward primer 5'-GAC TCT AGA GGA GAT AAC ATG TGG CTC TTG ACA GTT CTA -3' (the underlined nucleotides indicate an $\mathrm{Xba} I$ restriction sites and the reverse primer 5'CCG GGA TCC TTA ATG ATG ATG ATG ATG ATG CAC TTG AAG CTC CAA CTC AGG G-3' (the underlined nucleotides indicate a Bam $\mathrm{HI}$ restriction sites). Amplified cDNA was digested by Xba I and Bam HI then and cloned into a pLenti-3F vector (a gift from Dr. Fang Li's lab, University of Minnesota, St Paul, MN) digested with the same restriction enzymes. The expression of all constructs in pLenti-3F were confirmed using the sequencing primers 5'-CAT GGG AAA GCA TCG CTA CGA A-3' and 5'-TCA GAT TGA CCA CAT GCC CCT C-3'. Pseudo-lentiviral particles containing soluble canine CD16A or CD64 were generated using 293T cells and packaging vectors pMD2.G and pCMV-dR8.74psPAX2 (Addgene). Pseudo-lentiviral particles were transduced into the FreeStyle 293-F cells. The 293-F cell line was established under puromycin selection. The 293-F cells stably expressing soluble canine CD16A or CD64 were cultured in the FreeStyle ${ }^{\mathrm{TM}} 293$ Expression Medium (Thermo Fisher Scientific) and cell culture supernatants were harvested when cell density reached $2.5 \times 10^{6}$ / ml. Soluble canine CD16A or CD64 were purified from cell culture supernatants using a two-step purification procedure. First step, Ni-affinity chromatography. His-tagged proteins in cell culture supernatants were purified on a HisTrap HP His tag protein purification column (Cytiva, Marlborough, MA) according to the manufacture's protocol. Second step, Fast protein liquid chromatography. Soluble canine CD16A and CD64 from the first step purification were injected into a Superdex 200 Increase 10/300 GL column (Millipore-Sigma) on an AKTA pure protein purification system (Cytiva). The purity of proteins was $>95 \%$ as determined by SDS-PAGE.

\section{Statistical Analyses}

Comparison between two groups was done using Student $t$ test. Comparison between three or more groups was done using oneway ANOVA followed by Tukey honest significance post hoc test. Results are depicted as mean $\pm \mathrm{SD}$. The symbols used to represent the $\mathrm{p}$ values were as follows; ${ }^{\star *}, \mathrm{P} \leq 0.01$; ${ }^{\star * *}, \mathrm{P} \leq$ $0.001{ }^{* * * *}, \mathrm{P} \leq 0.0001$.

\section{RESULTS}

\section{Generation of Anti-cCD16A and cCD64 mAbs}

In humans, CD16 consists of two isoforms, CD16A and CD16B, encoded by two highly homologous genes (41). CD16A is a transmembrane protein expressed by lymphocytes and some monocytes, whereas CD16B is linked to the plasma membrane via a GPI anchor and primarily expressed by neutrophils $(42,43)$. Canine CD16 is a transmembrane protein and therefore we refer to it here as CD16A (16). The CD16B isoform does not exist in the canine genome or cDNA $(16,19)$. Currently, there are no commercially available mAbs specific to canine CD16A or CD64 or any that are cross-reactive that we are aware of. For canine
CD16A, this may be due to its relatively low levels of amino acid sequence identity and similarity with human CD16A (57.1\% and 71.7\%, respectively) (Supplementary Figure 1A). The amino acid sequence identity and similarity between canine CD64 and human CD64 are higher, $71.3 \%$ and $80.7 \%$, respectively (Supplementary Figure 1B). Reactivity by the anti-human CD16 mAb clone LNK16 with dog peripheral blood monocytes has been reported (44), though others demonstrated a lack of specific activity by the same $\mathrm{mAb}$ with dog PBMCs (45). We also observed no specific reactivity by LNK16 and several other anti-human CD16 or CD64 mAbs with dog leukocytes (data not shown). Therefore, we expressed soluble forms of canine CD16A and CD64 to immunize mice and for initial hybridoma screening by ELISA. The anti-CD16A mAb clone 4A5 and the anti-CD64 $\mathrm{mAb}$ clone 10 were used in all analyses described below. Due to the lack of commercially available canine NK cell lines, we used the human NK cell line NK-92 for stable expression of intact versions of canine CD16A or CD64. An advantage of these cells is that they lack expression of endogenous FcyRs (46). The canine CD16A and CD64 expression constructs were engineered with an N-terminus HA-tag for detection, as illustrated in Figure 1A. The retroviral vector used for transduction also expressed eGFP as a separate protein for an additional marker (Figure 1B). As shown in Figure 1C, the anti-CD16A mAb clone 4A5 (IgG1) demonstrated selective reactivity with NK-92 canine CD16A cells and the anti-CD64 mAb clone 10 (IgG1) demonstrated selective reactivity with NK-92 canine CD64 cells. Neither mAb stained NK-92 control cells (Figure 1C). We also observed similar reactivity by $4 \mathrm{~A} 5$ and 10 with recombinant soluble canine CD16A and CD64, respectively, by Western blotting (Figure 1D).

\section{Expression of CD16A and CD64 by Canine Leukocytes}

We used flow cytometry to examine the expression patterns of CD16A and CD64 by dog peripheral blood leukocytes. The general leukocyte populations of polymorphonuclear cells (PMNs), monocytes, and lymphocytes were identified based on their characteristic forward and side light-scattering and by their expression of well characterized markers, including CD4 (neutrophils and lymphocyte), CD14 (monocytes), and CD5 (T cells) (Figure 2A). The anti-canine CD16A clone 4A5 stained a subset of monocytes and lymphocytes, and for some dogs it marginally stained PMNs and/or a small subset of cells in this population (Figure 2A). This staining pattern was consistent for all the anti-canine CD16 mAbs generated, which had distinct complementarity-determining region nucleotide sequences from 4A5 (data not shown). In contrast to the expression pattern of CD16A, the anti-canine CD64 clone 10 stained essentially all PMNs and monocytes (Figure 2A). With some dogs, we noted a small subset of unstained cells in the PMN population (Figure 2A). Taken together, the expression patterns of CD16A and CD64 on dog peripheral blood leukocytes were very similar to that of their human orthologues on peripheral blood leukocytes (47).

We next examined dog peripheral blood lymphocytes to determine which subsets expressed CD16A based on available phenotypic markers. To assess its expression on T cells, we used 
A

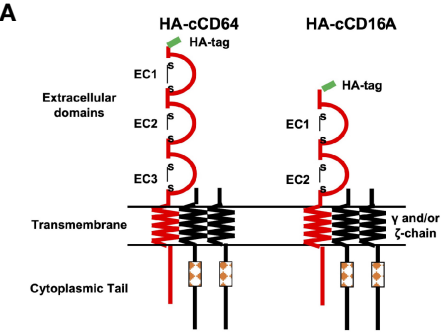

C

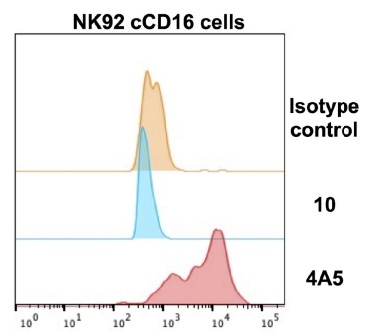

B
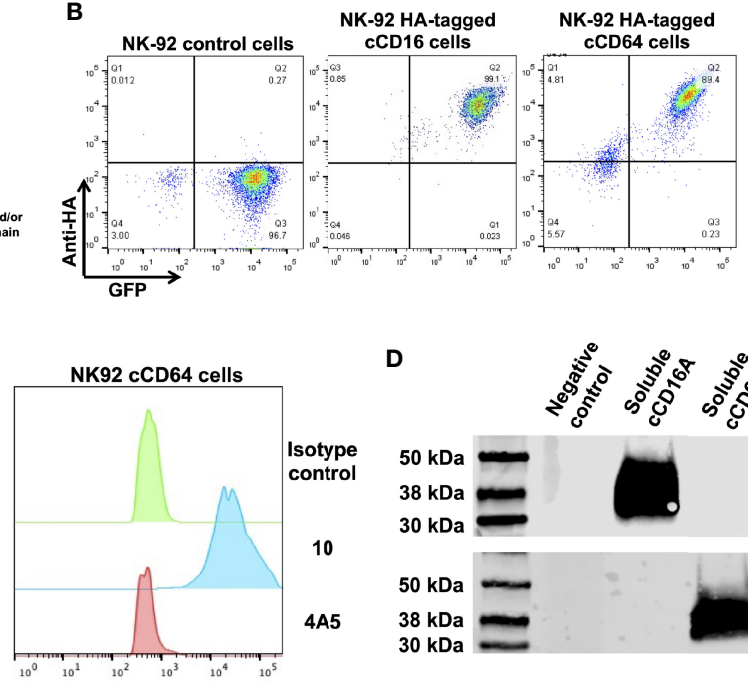

D

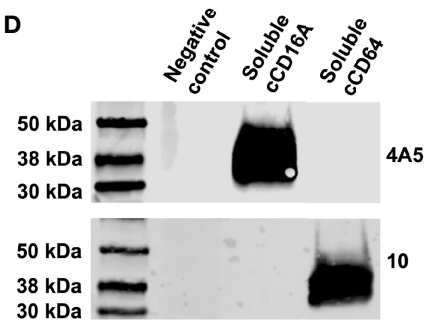

FIGURE 1 | Characterization of anti-canine CD16A and CD64 mAbs. (A) Schematic representation of recombinant intact canine CD16A and CD64 with an Nterminus HA-tag. The signaling adaptors FCR $\gamma$ and/or CD3 $\zeta$ ( $\gamma$ and/or $\zeta$ chain) non-covalently associate with human CD16A and CD64 as a homo or heterodimer. (B) Flow cytometric analyses of NK-92 cells transduced with an empty vector (control cells), NK-92 canine CD16A (cCD16A) cells, and NK-92 canine CD64 (cCD64) cells stained with an anti-HA mAb. (C) Flow cytometric analyses of NK-92 cCD16A cells and NK-92 cCD64 cells stained with an isotype-matched negative control mAb, the anti-canine CD16A mAb 4A5, or the anti-canine CD64 mAb 10. (D) Western blot analysis of recombinant soluble canine CD16A, recombinant soluble canine CD64, or soluble human CD177 (negative control) using the mAbs 4A5 or 10. Equal protein loading was confirmed by BCA. All data are representative of three independent experiments.

mAbs to canine $\alpha / \beta$ TCR, $\gamma / \delta$ TCR, CD8, CD4, and CD3. We found that canine CD16A was expressed on $\mathrm{T}$ cells, and that $\mathrm{CD}^{+} \mathrm{CD}^{2} 6 \mathrm{~A}^{+} \mathrm{T}$ cells (Figure 2B, panel 1) represented $3.08 \%( \pm$ $1.94 \% \mathrm{SD}$ ) of the peripheral blood lymphocytes in the group of dogs that were examined $(n=12)$. Moreover, $\mathrm{CD} 16 \mathrm{~A}^{+}$ lymphocytes primarily expressed an $\alpha / \beta$ TCR versus $\gamma / \delta$ TCR (Figure 2B, panels 2 and 3) and CD8 versus CD4 (Figure 2B, panels 4 and 5). CD16A expression was also observed on $\mathrm{CD}^{-}$ lymphocytes (Figure 2B, panel 1 ) as well as $\alpha / \beta \mathrm{TCR}^{-}$ lymphocytes (Figure 2B, panel 2), which usually was a smaller subset than $\mathrm{CD}^{+} \mathrm{CD}^{+} 16 \mathrm{~A}^{+} \mathrm{T}$ cells and consisted of $1.23 \% \pm$ $0.97 \% \mathrm{SD}, \mathrm{n}=12$ ) of the peripheral blood lymphocytes. B cells were identified by their expression of CD20 and CD22 (data not shown), and essentially none of these cells expressed CD16A (Figure 2B, panel 6).

In dogs, CD5 is typically classified as a canine $\mathrm{T}$ cell marker and is expressed at varying densities, referred to as $\mathrm{CD} 5^{\mathrm{dim}}$ and $\mathrm{CD} 5^{\text {bright }}$ (24). We detected CD16A expression on $\mathrm{CD}^{-}$and $\mathrm{CD} 5^{\mathrm{dim}}$ lymphocytes, but not on CD5 $5^{\text {bright }}$ lymphocytes (Figure 2B, panel 7). In most dogs we observed that $\mathrm{CD} 5^{\text {dim }} \mathrm{CD} 16 \mathrm{~A}^{+}$lymphocytes were the predominant population, but in some dogs $\mathrm{CD}^{-} \mathrm{CD} 16 \mathrm{~A}^{+}$ lymphocytes were an equivalent or the predominant population (Figure 2C). Within the $\mathrm{CD}_{16 \mathrm{~A}^{+}}$lymphocyte population, CD5 expression corresponded with $\mathrm{CD} 3$ expression. That is, $\mathrm{CD}_{16 \mathrm{~A}^{+}}$ lymphocytes were either $\mathrm{CD}^{+} \mathrm{CD}^{+}$or $\mathrm{CD}^{-} \mathrm{CD}^{-}$(Figure $2 \mathrm{C}$ ). In humans, the non- $\mathrm{B}$ cell, $\mathrm{CD}^{-} \mathrm{CD}^{-} \mathrm{CD}^{-} 6 \mathrm{~A}^{+}$lymphocyte population represents NK cells (48). CD56 and CD94 are broad markers of human NK cells $(49,50)$. CD56 is not an NK cell marker in dogs $(51,52)$, whereas CD94 has been reported to be expressed by dog NK and NK T cells (53). Using a commercially available antihuman CD94 mAb that cross-reacts with canine CD94 (53), we found it stained a portion of $\mathrm{CD}^{-} \mathrm{CD}^{-} \mathrm{A}^{+}$and $\mathrm{CD}^{+} \mathrm{CD}^{+} 16 \mathrm{~A}^{+}$ lymphocytes, which varied between dogs (Figure 2D). The above findings thus indicate that $\mathrm{CD} 16^{+}$lymphocytes in the dog consist of NK cells and T cells (e.g., NK T cells), and that the latter is the predominant population, which contrasts with humans $(48,54,55)$.

\section{Ectodomain Shedding of Canine CD16A}

Human CD16A undergoes a rapid downregulation in expression by a proteolytic process mediated by a disintegrin and metalloproteinase-17 (ADAM17) upon cell activation with various stimuli $(23,40,56,57)$. For instance, the treatment of human leukocytes with the phorbol ester PMA induces efficient CD16A downregulation by ADAM17 (40). We found that this also occurred upon the activation of canine leukocytes with PMA. For instance, in Figure 3, CD16A levels on CD5 ${ }^{\text {dim }}$ lymphocytes are shown before and after PMA activation. We have previously reported on ADAM17 activity in dog neutrophils and that it can be blocked by an ADAM17 mAb (33). This $\mathrm{mAb}$ also blocked the downregulation of CD16A on activated canine lymphocytes (Figure 3). Taken together, our findings reveal a similar regulation of human and canine CD16A by ADAM17, a process that does not occur for mouse CD16 (23).

\section{Induction of ADCC by Canine CD16A and CD64}

Human CD16A is a potent activating receptor that induces ADCC upon engaging antibodies attached to target cells (1). 
A

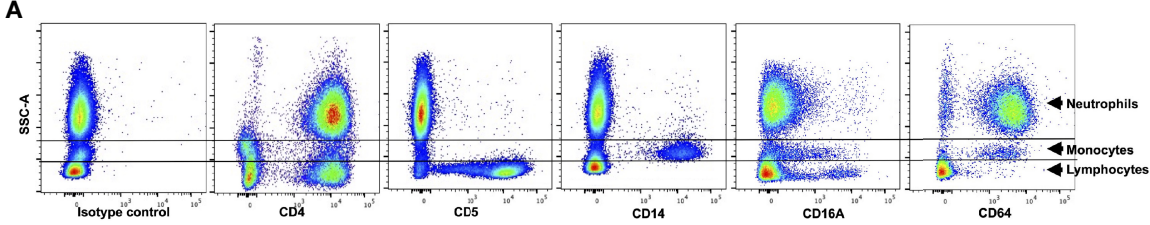

B
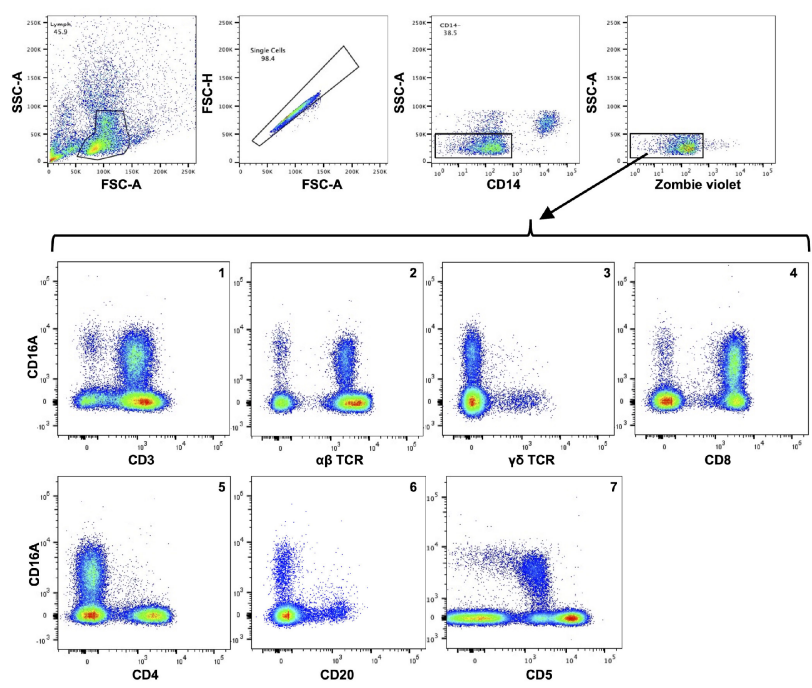

C
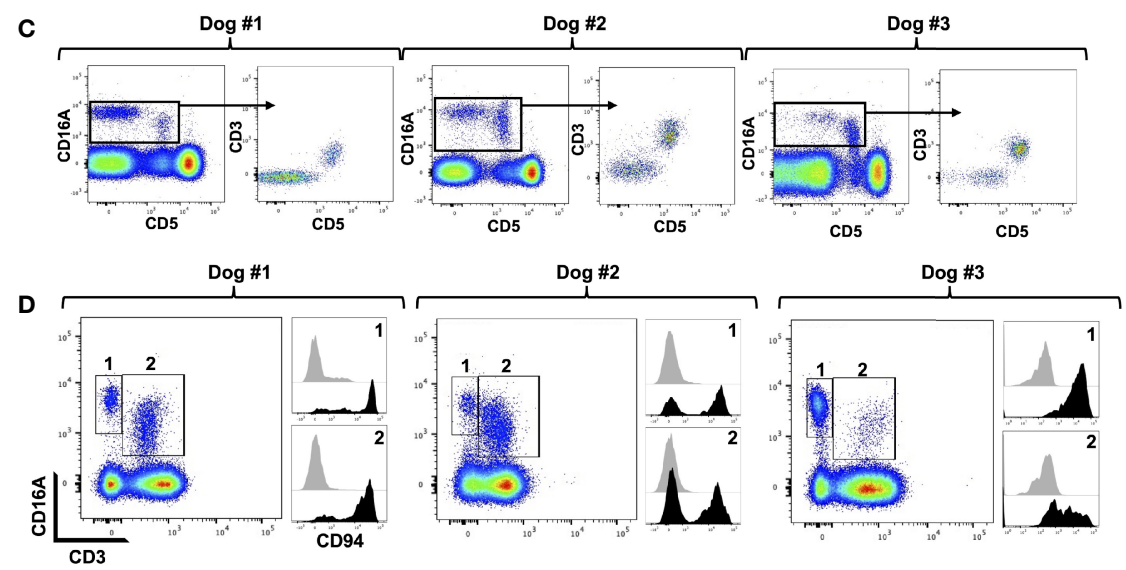

FIGURE 2 | CD16A and CD64 expression by canine leukocyte subsets. (A) Canine peripheral blood leukocytes were stained for the indicated markers and examined by flow cytometry. The $y$-axis = light side scatter area (SSC-A) and the $x$-axis $=$ Log 10 fluorescence. Data are representative of multiple independent experiments using leukocytes from separate canine donors. (B) CD16A is expressed by T cells and non-B cell, non-T cell lymphocytes. The top panels show the gating strategy on peripheral blood mononuclear cells to examine single cell, viable, lymphocytes. The gating strategy was used in B-C. The bottom panels show the expression of CD16A on various lymphocyte populations using the indicated markers. All data are representative of multiple independent experiments using leukocytes from separate canine donors. (C) CD16A expression on $\mathrm{CD5}^{-}$and $\mathrm{CD}^{+}$lymphocytes. For each dog examined, CD16A versus CD5 staining of lymphocytes was determined (left panel). From this plot, CD16 ${ }^{+}$cells were gated and their expression of CD3 versus CD5 determined. (D) Expression of CD94 by $\mathrm{CD}^{-} \mathrm{CD}_{16}{ }^{+}$and $\mathrm{CD}^{+} \mathrm{CD}_{16}{ }^{+}$lymphocytes. These populations were gated on for each dog examined (left panel) and their staining levels of CD94 were determined (right panel), as indicated by the corresponding numbers. The black filled histograms represent CD94 staining, and the grey filled histograms represent isotypematched negative control staining. For panels (C, D) different dogs were examined.

We directly tested whether canine CD16A could induce ADCC. For this experiment, NK-92 cells were transduced with intact canine CD16A that lacked an HA-tag due to the potential it might interfere with IgG binding. Canine CD16A expression was verified using the anti-canine $\mathrm{CD} 16 \mathrm{~A}$ mAb $4 \mathrm{~A} 5$ (data not shown). To avoid a xenogeneic response between NK-92 cells and canine target cells, as has been reported by others (58), we used the human ovarian cancer cell line SKOV-3 as target cells that we transduced to express canine CD20 (Figure 4A). Like human IgGs, canine IgGs consist of four subclasses (IgG 1, 2, 3, and 4 also referred to as A, B, C, and D) $(16,59)$. Canine IgG2 (IgGB) is the functional analog of human IgG1 and it binds to 


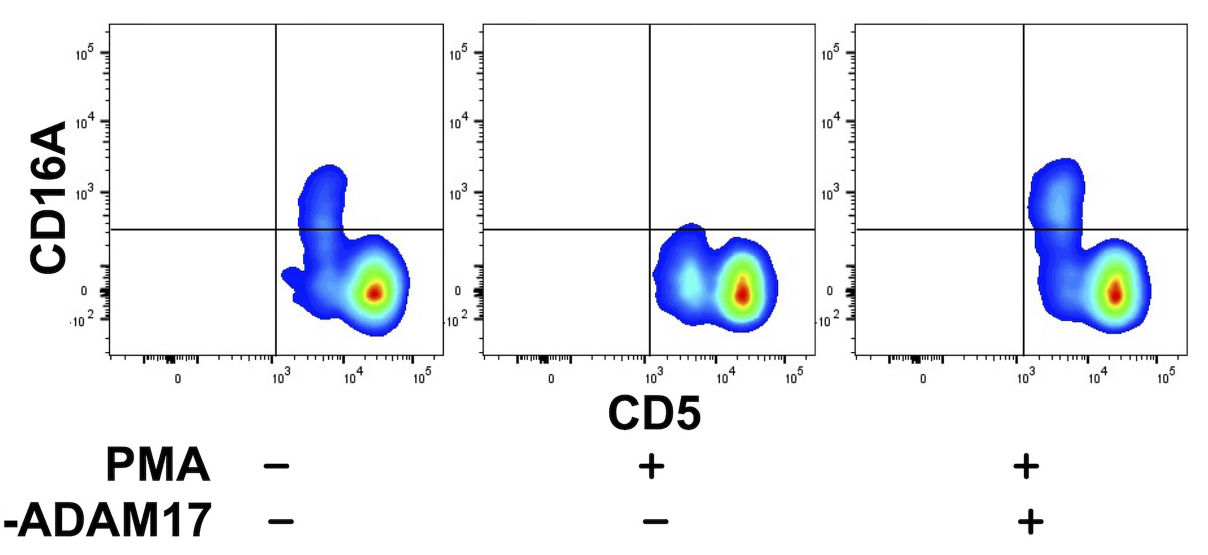

FIGURE 3 | Canine CD16A is downregulated by ADAM17 upon lymphocyte activation. Canine peripheral blood mononuclear cells were treated with or without PMA in the presence or absence of an ADAM17 function blocking mAb. Relative cell-staining levels of CD16A on CD5 dim or CD5 ${ }^{\text {bright }}$ cells were determined by flow cytometry. All density plots show representative data of three independent experiments using leukocytes from separate canine donors.

canine CD16A and canine CD64 (16). To target canine CD20, we used a commercially available "caninized" mAb containing a canine IgG2 Fc region (Figure 4B). We observed that NK-92 cells expressing canine CD16A mediated significantly higher levels of cytolysis in the presence of the anti-CD20 mAb when compared to cells in the absence of the $\mathrm{mAb}$ at various effector: target (E:T) ratios (Figure 4C).

Human and canine CD16A binds to IgG with low affinity as well as reduced avidity when downregulated in expression by ADAM17 upon NK cell activation. These may serve as checkpoint processes for maintaining immune homeostasis, but they also reduce the efficacy of anti-tumor therapeutic mAbs (3). To address this, we have engineered human NK cells with recombinant versions of $\operatorname{CD} 64(14,17,18)$, the only high affinity Fc $\gamma R(10,60)$. Human CD64 binds to the same IgG isotypes as CD16A (10), as is also the case for canine CD64 (16), and it signals the same as CD16A by noncovalent association with $\mathrm{FcR} \gamma$ and/or $\mathrm{CD} 3 \zeta$ (18). Moreover, CD64 is not cleaved by ADAM17 (17). Figure 5A shows that NK-92 cells expressing canine CD64 also effectively mediated ADCC of SKOV-3 canine CD20 cells in the presence of a caninized antiCD20 mAb. Due to the high affinity state of CD64, we found that engineered NK-92 cells expressing human CD64 could be armed with tumor-targeting mAbs and mediate $\operatorname{ADCC}(17,18)$. NK-92 cells expressing canine CD64 also bound soluble monomeric canine IgG and at higher levels than NK-92 cells expressing canine CD16A (Figure 5B). Additionally, NK-92 cells expressing canine CD64 could be armed with a caninized anti-CD20 mAb and mediate ADCC of SKOV-3-cCD20 cells (Figure 5C). Collectively, our data demonstrate that canine CD16 and CD64 can induce ADCC by NK-92 cells, similar to their human orthologues.

\section{DISCUSSION}

Human CD64 and CD16A play a critical role in the effector activities of anti-tumor therapeutic mAbs (15). Both Fc $\gamma$ Rs have been cloned from dog leukocytes and their IgG binding characteristics examined (16). However, their cell surface expression patterns on dog leukocytes have not been previously determined. We generated mAbs to canine CD64 and CD16A and show their expression on myeloid and lymphoid leukocyte subsets in the dog, which in general was similar to humans (47). A closer look at canine lymphocytes revealed CD16A expression on $\mathrm{CD}^{+} \mathrm{T}$ cells and $\mathrm{CD}^{-}$lymphocytes, but not on $\mathrm{B}$ cells. Interesting is that canine $\mathrm{CD}_{16 \mathrm{~A}^{+}}$lymphocytes were predominantly in the $\mathrm{CD}^{+}$ fraction, and expressed an $\alpha / \beta$ TCR and CD8, whereas in humans, $\mathrm{CD} 16 \mathrm{~A}^{+}$lymphocytes primarily occur in the $\mathrm{CD}^{-}$fraction (48). Though, it has been reported that the proportion of $\alpha / \beta \mathrm{TCR}^{+} \mathrm{CD} 8^{+}$ $\mathrm{CD}_{16 \mathrm{~A}^{+}} \mathrm{T}$ cells in humans can increase during certain viral infections, and that these cells demonstrated NK cell properties (55). Huang et al., reported that the $\mathrm{CD} 5^{\mathrm{dim}}$ canine lymphocyte population was primarily $\alpha / \beta \mathrm{TCR}^{+}$and $\mathrm{CD}^{+}$with NK cell-like effector functions (38). We speculate that canine NK T cells include $\mathrm{CD}^{+}{ }^{+} \mathrm{CD} 5^{\mathrm{dim}} \alpha / \beta \mathrm{TCR}^{+} \mathrm{CD} 8^{+} \mathrm{CD} 94^{+} \mathrm{CD} 16 \mathrm{~A}^{+}$cells, and it will be interesting to examine their effector functions in future studies.

Canine NK cells are phenotypically distinguished based on their lack of B cell markers, CD3, CD4, and TCRs $(24,25)$. $\mathrm{CD} 5{ }^{\text {bright }}$ lymphocytes in the dog have been classified as $\mathrm{T}$ cell (24); however, there are conflicting views on CD5 expression by canine NK cells, which have been reported as $\mathrm{CD} 5^{+/-}$and $\mathrm{CD} 5^{\mathrm{dim}}$ $(27,30,38)$. Both populations have been shown to mediate natural cytotoxicity and $\operatorname{ADCC}(27,28,30,31,38)$. We observed that CD5 expression levels on $\mathrm{CD}_{16 \mathrm{~A}^{+}}$lymphocytes ranged from negative to dim, and this directly corresponded with their CD3 expression. Thus, canine $\mathrm{CD}_{16 \mathrm{~A}^{+}}$lymphocytes appear to consist of $\mathrm{CD}^{+}$ $\mathrm{CD}^{\mathrm{dim}} \mathrm{T}$ cells, as discussed above, and $\mathrm{CD}^{-} \mathrm{CD}^{-} \mathrm{CD} 20^{-}$(or $\mathrm{CD}_{2}{ }^{-}$) lymphocytes. The phenotypic characterization of canine NK cells is at this point is a work in progress. NK cell markers detected by antibodies consist of CD94 and NKp46 (24). We show that $\mathrm{CD} 94$ expression varied on $\mathrm{CD}^{-} \mathrm{CD}^{-} 6 \mathrm{~A}^{+}$lymphocytes, as well $\mathrm{CD}^{+} \mathrm{CD}^{+} 6 \mathrm{~A}^{+}$lymphocytes. NKp46 expression has been reported to also vary on dog peripheral blood NK cells, and its 


\section{A}

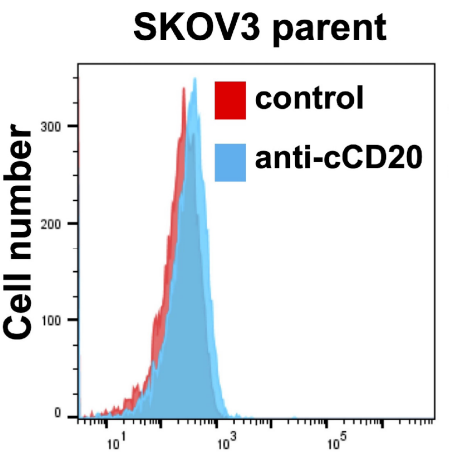

SKOV3-cCD20

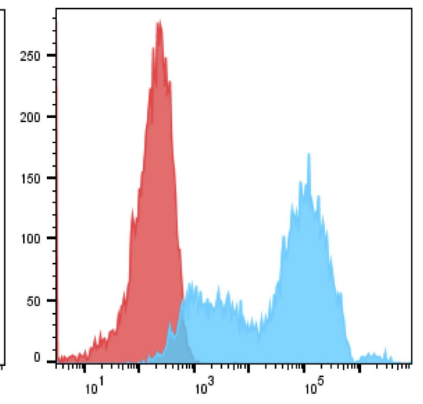

B

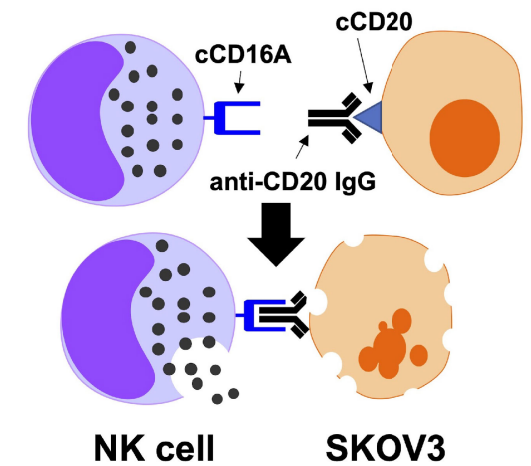

c

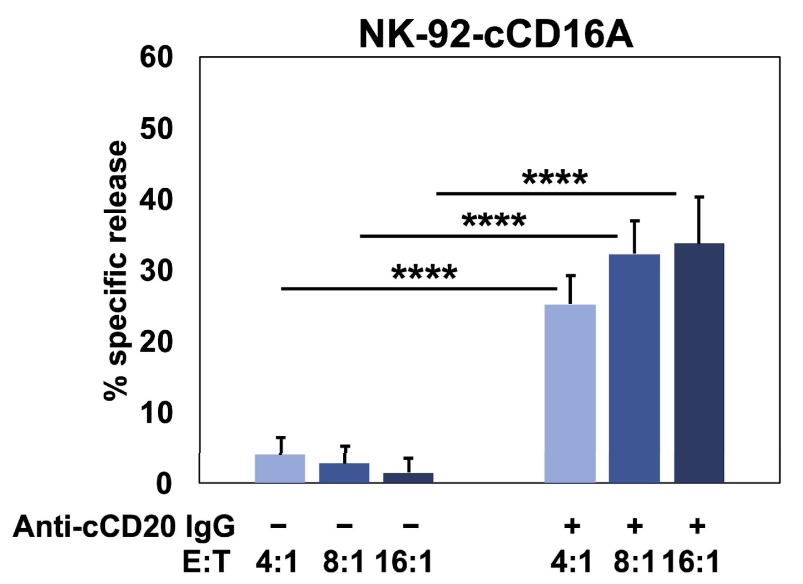

FIGURE 4 | NK-92 cells expressing canine CD16A mediate ADCC. (A) SKOV-3 parental cells and SKOV-3-canine CD20 (cCD20) cells were stained with an anticanine CD20 mAb or an isotype-matched negative control mAb (control) and examined by flow cytometry. (B) Schematic representation of ADCC. SKOV-3-canine CD20 cells treated with a caninized anti-canine CD20 mAb in the presence of NK-92 canine CD16A (cCD16A) cells. (C) NK-92 canine CD16A cells were incubated with SKOV-3 canine CD20 cells at the indicated E:T ratios in the presence or absence of a caninized anti-canine CD20 mAb for $2 \mathrm{~h}$ at $37{ }^{\circ} \mathrm{C}$. Data are represented as \% specific release and the mean \pm SD of 3 independent experiments is shown. Statistical significance is indicated as *** $p<0.0001$.

expression appears to indicate recent activation and expansion $(27,29,31,61,62)$. Using the only commercially available anticanine NKp46 mAb, we observed inconsistent staining of dog peripheral blood lymphocytes, which at times did not stain above an isotype-matched negative control $\mathrm{mAb}$ (data not shown). As is the case in humans (1), CD16A may represent a pan-marker of mature NK cells in the peripheral blood of dogs.

Our study shows that the clone $4 \mathrm{~A} 5 \mathrm{mAb}$ recognizes canine CD16A and not CD64. CD32B is the only other expressed canine
Fc $\gamma \mathrm{R}$ (16). We did not directly demonstrate that 4A5 does not recognize canine $\mathrm{CD} 32 \mathrm{~B}$; however, we feel this is unlikely considering that full-length canine CD16A and CD32B have only $\sim 30 \%$ amino acid identity (data not shown). In addition, CD32B is expressed by human and mouse $B$ cells and functions as an inhibitory receptor that blocks antibody production (10). We did not observe 4A5 staining of canine B cells.

Mouse leukocytes express in addition to classic CD16, CD16-2 (FcyRIV), an orthologue of human CD16A $(10,60)$. A review article 
A

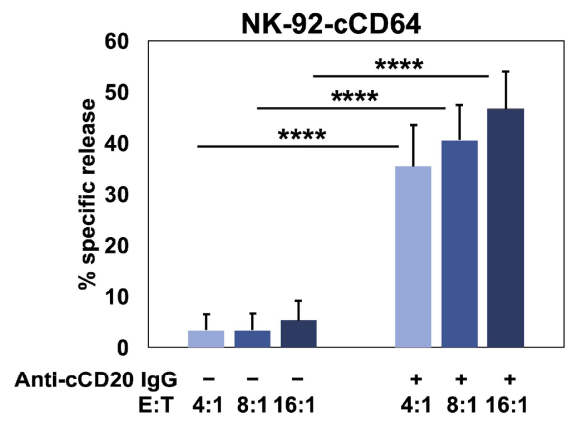

B

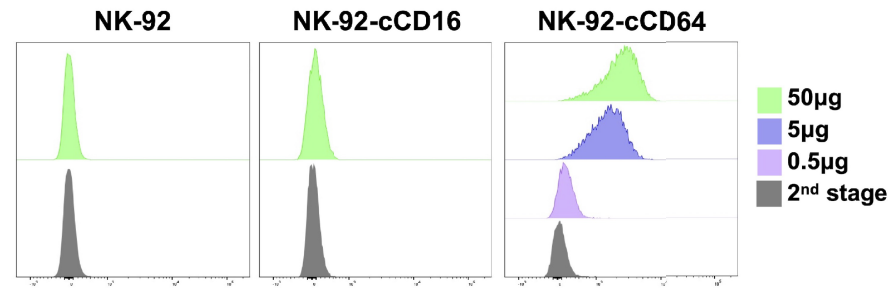

C

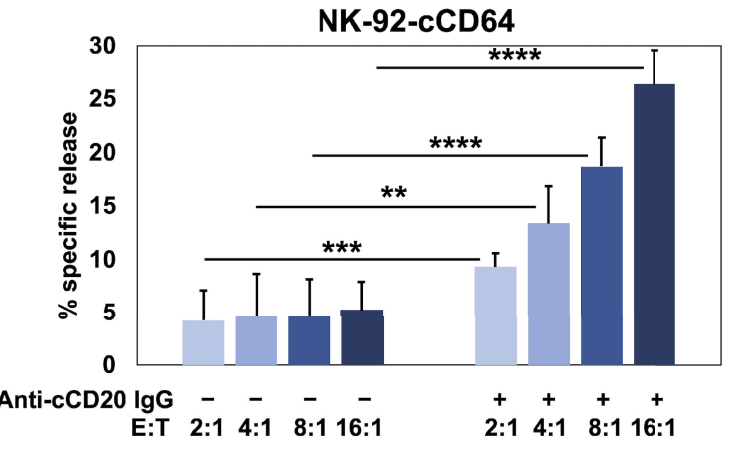

FIGURE 5 | NK-92 cells expressing canine CD64 mediate ADCC when armed with a tumor-targeting mAb. (A) NK-92 canine CD64 (cCD64) cells were incubated with SKOV-3 canine CD2O cells at the indicated E:T ratios in the presence or absence of a caninized anti-canine CD20 mAb for $2 \mathrm{~h}$ at $37^{\circ} \mathrm{C}$. Data are represented as $\%$ specific release and the mean \pm SD of 3 independent experiments is shown. Statistical significance is indicated as ${ }^{* \star \star *} p<0.0001$. (B) NK-92-cCD16A and NK92-cCD64 cells were incubated with or without biotinylated canine $\operatorname{lgG}$ at various concentrations for $1 \mathrm{~h}$ at $37^{\circ} \mathrm{C}$, washed, stained with fluorophore-conjugated streptavidin, and analyzed by flow cytometry. Data are representative of at least 3 independent experiments. (C) NK-92 canine CD64 cells were incubated in the presence or absence of caninized anti-canine CD2O mAb $(5 \mu \mathrm{g} / \mathrm{ml})$, washed, and exposed to SKOV-3 canine CD2O cells at the indicated E:T ratios for $2 \mathrm{~h}$ at $37^{\circ} \mathrm{C}$. Data are represented as \% specific release and the mean \pm SD of 3 independent experiments is shown. Statistical significance is indicated as ${ }^{\star *} p<0.01$, ${ }^{* \star \star} p<0.001,{ }^{\star \star \star \star} p<0.0001$.

by Nimmerjahn et al. in 2006 reported on the presence of an FCGR4 gene on chromosome 38 in the dog (19). This was based on an early rough draft of the dog genome sequence from 16 years ago. According to the most updated Canis lupus familiaris assembly ROS_Cfam_1.0 (RefSeq: GCF_014441545.1), chromosome 38 of C. lupus (updated on December 23, 2021, Chr 38_21,137,358.21, 146,800, Length: 9,443 nucleotides) contains the FCGR3A gene (also known as LOC478984), which encodes for the low affinity IgG Fc receptor CD16A, and lacks the FCGR4 gene. Humans also lack this gene $(10,60)$.

We directly show that canine CD16A when expressed in the human NK cell line NK-92 can induce ADCC. Others have reported that NK-92 cells expressing a canine CD16A fusion protein consisting of the extracellular region of canine CD16A and the transmembrane and intracellular regions of canine $\mathrm{FcR} \gamma$ also mediated ADCC (58). Human CD16A signaling is normally mediated by a non-covalent association with the signaling adapters FcR $\gamma$ and/or CD3 $\zeta(1,63,64)$. NK-92 cells express FcR $\gamma$ and CD3 $\zeta$ (65), and therefore canine CD16A likely associated with these signaling adaptors to induce ADCC. Indeed, seven amino acids in the transmembrane region of human CD16A have been shown to be critical for FcR $\gamma$ and $\mathrm{CD} 3 \zeta$ association (65), and all seven amino acids are conserved in the transmembrane region of canine CD16A (Supplementary Figure 1A).

A critical effector function of several clinically successful mAbs targeting tumors is ADCC (66); however, CD16A undergoes rapid shedding from the cell surface of NK cells by ADAM17 following its signaling or by various other stimuli $(23,40,56,57)$. This appears to 
reduce the efficacy of tumor $\mathrm{mAb}$ therapies, and perhaps especially so in the tumor microenvironment (3). Indeed, CD16A downregulation has been reported to occur by NK cells in the tumor microenvironment of ovarian cancer (67). ADAM17 activity has been demonstrated in canine leukocytes (33), and we show in this study that blocking the metalloprotease prevented CD16A downregulation upon canine lymphocyte activation. Further studies will be required to determine if canine CD16A is cleaved at the same location as human CD16A and the functional effects of blocking this process. Human NK cells expressing a non-cleavable version of CD16A or upon blocking ADAM17 activity demonstrated increased killing of tumor cells by ADCC and production of IFN $\gamma(5-7)$, and thus this may be an approach to enhance $\mathrm{ADCC}$ by $\mathrm{CD} 16 \mathrm{~A}^{+}$canine lymphocytes.

Another property of CD16A that appears to decrease the efficacy of mAb therapies is that it is a low affinity member of the Fc $\gamma \mathrm{R}$ family. Indeed, clinical studies in humans have shown that increasing the affinity by which NK cells engage anti-tumor mAbs significantly improved patient outcome $(11,12,68,69)$. This is an active area of research that includes approaches such as modifying the Fc region of anti-tumor antibodies or the Fc $\gamma \mathrm{R}$ on NK cells (14, $15,66)$. For the latter, we have engineered human NK cells to express recombinant versions of human $\operatorname{CD} 64(17,18)$, the only high affinity IgG Fc receptor in humans and dogs $(10,16)$. Human CD64 is normally expressed by myeloid cells and not NK cells (10). We observed the same CD64 expression pattern in dogs. Similar to canine CD16A, canine CD64 expression in NK-92 cells induced ADCC, and due to its high affinity state, monomeric canine IgG could be adsorbed to these cells. Additionally, NK-92 canine CD64 cells armed with a caninized anti-canine CD20 mAb effectively killed target cells expressing canine CD20. NK-92 canine CD64 cells appeared to have higher ADCC activity when anti-canine CD20 $\mathrm{mAb}$ was added to the assay compared to NK-92 canine CD64 cells armed with anti-canine CD20 mAb; however, we did not perform a direct comparison. Nevertheless, it is possible that some of the adsorbed mAb internalized (especially if antibody aggregates were present) or dissociated from CD64, leading to lower ADCC activity by the armed NK-92 canine CD64 cells. It will be interesting to determine in future studies if primary dog NK cells or T cells can be engineered to express canine CD64 and if this enhances their ADCC potency. NK cells, due to their lack of graft-vs-host response, expressing canine CD64 could provide an off-the-shelf adoptive cell therapy option used in combination with assorted antitumor targeting mAbs. This would provide broad tumor antigen targeting to reduce tumor antigen escape and for treating various malignancies. The development of $\mathrm{mAbs}$ that target tumor antigens in dogs and induce ADCC has been minimal at this time (70). However, as tools and our understanding about canine immune cells rapidly increase, it is likely a surge in immunotherapies for dogs will follow.

Dogs also offer a key animal model for the translation of immunotherapies. The study of ADCC in rodent syngeneic tumor models is limited by species differences in immune cell effector functions, including significant differences in human and mouse CD16 expression and function (see Introduction). The dog spontaneous cancer model incorporates heterogeneous disease and an intact immune system with many similarities to humans to help determine the mechanisms that underlie success and failure of immunotherapies (24-26). We have extended the current understanding of the dog immune system by demonstrating phenotypic and functional characteristics of canine CD16A and CD64 to advance utilizing these Fc $\gamma$ Rs for therapeutic approaches.

\section{DATA AVAILABILITY STATEMENT}

The raw data supporting the conclusions of this article will be made available by the authors, without undue reservation.

\section{ETHICS STATEMENT}

The animal study was reviewed and approved by Institutional Animal Care and Use Committee of the University of Minnesota. Written informed consent was obtained from the owners for the participation of their animals in this study.

\section{AUTHOR CONTRIBUTIONS}

$\mathrm{RH}, \mathrm{YL}, \mathrm{KS}, \mathrm{SW}, \mathrm{CL}, \mathrm{CZ}$, and CF designed the experiments, collected, assembled, analyzed, and interpreted the data. JW and BW designed the experiments, interpreted the data, and wrote the manuscript. $\mathrm{PM}$ contributed vital reagents. JM and $\mathrm{AB}$ interpreted the data. All authors contributed to the manuscript preparation as well as read and approved the submitted version.

\section{FUNDING}

This work was supported by University of Minnesota College of Veterinary Medicine Comparative Medicine Signature Program Grant (to BW, JW, AB); University of Minnesota Animal Cancer Care and Research Program Canine Cancer Charitable Grant and GreyLong Gift (to BW); Howard Hughes Medical Institute and Burroughs Wellcome Fund Medical Research Fellowship (to KS); NIH UL1TR002494 supporting the University of Minnesota Clinical and Translational Science Institute K-R01 Scholar Award (to AB), and NIH P30 CA77598 supporting the University of Minnesota, Masonic Cancer Center, Flow Cytometry resource.

\section{ACKNOWLEDGMENTS}

We would like to thank Kathy Stuebner and Amber Winter from the University of Minnesota, College of Veterinary Medicine, Clinical Investigation Center for assistance in acquiring canine peripheral blood samples, and Taylor DePauw with flow cytometry assistance.

\section{SUPPLEMENTARY MATERIAL}

The Supplementary Material for this article can be found online at: https://www.frontiersin.org/articles/10.3389/fimmu.2022.841859/ full\#supplementary-material

Supplementary Figure 1 | Amino acid alignment of human and canine CD16A or canine CD64. The amino acid sequences of human and canine CD16A and CD64 
are from the NCBI reference sequences (human CD16: X52645.1; canine CD16A: XM_022415348; human CD64: X14356.1; canine CD64: NM_001002976). The amino acid sequence of the human CD16A and CD64 transmembrane regions

\section{REFERENCES}

1. Miller JS, Lanier LL. Natural Killer Cells in Cancer Immunotherapy. Annu Rev Cancer Biol (2019) 3:77-103. doi: 10.1146/annurev-cancerbio-030518055653

2. Alderson KL, Sondel PM. Clinical Cancer Therapy by NK Cells via AntibodyDependent Cell-Mediated Cytotoxicity. J BioMed Biotechnol (2011) 2011:379123. doi: 10.1155/2011/379123

3. Wu J, Mishra HK, Walcheck B. Role of ADAM17 as a Regulatory Checkpoint of CD16A in NK Cells and as a Potential Target for Cancer Immunotherapy. J Leukoc Biol (2019) 105(6):1297-303. doi: 10.1002/JLB.2MR1218-501R

4. Zahavi D, Weiner L. Monoclonal Antibodies in Cancer Therapy. Antibodies (Basel) (2020) 9(3):1-20. doi: 10.3390/antib9030034

5. Mishra HK, Pore N, Michelotti EF, Walcheck B. Anti-ADAM17 Monoclonal Antibody MEDI3622 Increases IFNgamma Production by Human NK Cells in the Presence of Antibody-Bound Tumor Cells. Cancer Immunol Immunother (2018) 67(9):1407-16. doi: 10.1007/s00262-018-2193-1

6. Pomeroy EJ, Hunzeker JT, Kluesner MG, Lahr WS, Smeester BA, Crosby MR, et al. A Genetically Engineered Primary Human Natural Killer Cell Platform for Cancer Immunotherapy. Mol Ther (2020) 28(1):52-63. doi: 10.1016/ j.ymthe.2019.10.009

7. Zhu H, Blum RH, Bjordahl R, Gaidarova S, Rogers P, Lee TT, et al. Pluripotent Stem Cell-Derived NK Cells With High-Affinity Noncleavable CD16a Mediate Improved Antitumor Activity. Blood (2020) 135(6):399-410. doi: 10.1182/blood.2019000621

8. Wu J, Edberg JC, Redecha PB, Bansal V, Guyre PM, Coleman K, et al. A Novel Polymorphism of FcgammaRIIIa (CD16) Alters Receptor Function and Predisposes to Autoimmune Disease. J Clin Invest (1997) 100(5):1059-70. doi: 10.1172/JCI119616

9. Koene HR, Kleijer M, Algra J, Roos D, von dem Borne AE, de Haas M. Fc gammaRIIIa-158v/F Polymorphism Influences the Binding of IgG by Natural Killer Cell Fc gammaRIIIa, Independently of the Fc gammaRIIIa-481/R/H Phenotype. Blood (1997) 90(3):1109-14. doi: 10.1182/blood.V90.3.1109

10. Bruhns P. Properties of Mouse and Human IgG Receptors and Their Contribution to Disease Models. Blood (2012) 119(24):5640-9. doi: 10.1182/blood-2012-01-380121

11. Cartron G, Dacheux L, Salles G, Solal-Celigny P, Bardos P, Colombat P, et al. Therapeutic Activity of Humanized Anti-CD20 Monoclonal Antibody and Polymorphism in IgG Fc Receptor FcgammaRIIIa Gene. Blood (2002) 99 (3):754-8. doi: 10.1182/blood.v99.3.754

12. Musolino A, Naldi N, Bortesi B, Pezzuolo D, Capelletti M, Missale G, et al. Immunoglobulin G Fragment C Receptor Polymorphisms and Clinical Efficacy of Trastuzumab-Based Therapy in Patients With HER-2/NeuPositive Metastatic Breast Cancer. J Clin Oncol (2008) 26(11):1789-96. doi: 10.1200/JCO.2007.14.8957

13. Bibeau F, Lopez-Crapez E, Di Fiore F, Thezenas S, Ychou M, Blanchard F, et al. Impact of Fc\{gamma\}RIIa-Fc\{gamma\}RIIIa Polymorphisms and KRAS Mutations on the Clinical Outcome of Patients With Metastatic Colorectal Cancer Treated With Cetuximab Plus Irinotecan. J Clin Oncol (2009) 27 (7):1122-9. doi: 10.1200/JCO.2008.18.0463

14. Walcheck B, Wu J. iNK-CD64/16A Cells: A Promising Approach for ADCC? Expert Opin Biol Ther (2019) 19(12):12290-32. doi: 10.1080/14712598. 2019.1667974

15. Dixon KJ, Wu J, Walcheck B. Engineering Anti-Tumor Monoclonal Antibodies and Fc Receptors to Enhance ADCC by Human NK Cells. Cancers (Basel) (2021) 13(2):1-13. doi: 10.3390/cancers 13020312

16. Bergeron LM, McCandless EE, Dunham S, Dunkle B, Zhu Y, Shelly J, et al. Comparative Functional Characterization of Canine IgG Subclasses. Vet Immunol Immunopathol (2014) 157(1-2):31-41. doi: 10.1016/j.vetimm. 2013.10.018

17. Snyder KM, Hullsiek R, Mishra HK, Mendez DC, Li Y, Rogich A, et al. Expression of a Recombinant High Affinity IgG Fc Receptor by Engineered (underlined) is based on a previous study (71). (A) Alignment of human and canine CD16A. The red boxed letters represent amino acids critical for association with the signaling adaptors FCR $\gamma$ and $C D 3 \zeta$ (65). (B) Alignment of human and canine CD64.
NK Cells as a Docking Platform for Therapeutic Mabs to Target Cancer Cells. Front Immunol (2018) 9:2873. doi: 10.3389/fimmu.2018.02873

18. Hintz HM, Snyder KM, Wu J, Hullsiek R, Dahlvang JD, Hart GT, et al. Simultaneous Engagement of Tumor and Stroma Targeting Antibodies by Engineered NK-92 Cells Expressing CD64 Controls Prostate Cancer Growth. Cancer Immunol Res (2021) 9(11):1270-82. doi: 10.1158/23266066.CIR-21-0178

19. Nimmerjahn F, Ravetch JV. Fcgamma Receptors: Old Friends and New Family Members. Immunity (2006) 24(1):19-28. doi: 10.1016/ j.immuni.2005.11.010

20. Nimmerjahn F, Bruhns P, Horiuchi K, Ravetch JV. FcgammaRIV: A Novel FcR With Distinct IgG Subclass Specificity. Immunity (2005) 23(1):41-51. doi: 10.1016/j.immuni.2005.05.010

21. Hirano M, Davis RS, Fine WD, Nakamura S, Shimizu K, Yagi H, et al. IgEb Immune Complexes Activate Macrophages Through FcgammaRIV Binding. Nat Immunol (2007) 8(7):762-71. doi: 10.1038/ni1477

22. Mancardi DA, Iannascoli B, Hoos S, England P, Daeron M, Bruhns P. FcgammaRIV Is a Mouse IgE Receptor That Resembles Macrophage FcepsilonRI in Humans and Promotes IgE-Induced Lung Inflammation. J Clin Invest (2008) 118(11):3738-50. doi: 10.1172/JCI36452

23. Wang Y, Wu J, Newton R, Bahaie NS, Long C, Walcheck B. ADAM17 Cleaves CD16b (FcgammaRIIIb) in Human Neutrophils. Biochim Biophys Acta (2013) 1833(3):680-5. doi: 10.1016/j.bbamcr.2012.11.027

24. Gingrich AA, Modiano JF, Canter RJ. Characterization and Potential Applications of Dog Natural Killer Cells in Cancer Immunotherapy. J Clin Med (2019) 8(11):1-18. doi: 10.3390/jcm8111802

25. Kisseberth WC, Lee DA. Adoptive Natural Killer Cell Immunotherapy for Canine Osteosarcoma. Front Vet Sci (2021) 8:672361. doi: 10.3389/ fvets.2021.672361

26. Gingrich AA, Reiter TE, Judge SJ, York D, Yanagisawa M, Razmara A, et al. Comparative Immunogenomics of Canine Natural Killer Cells as Immunotherapy Target. Front Immunol (2021) 12:670309. doi: 10.3389/ fimmu.2021.670309

27. Foltz JA, Somanchi SS, Yang Y, Aquino-Lopez A, Bishop EE, Lee DA. NCR1 Expression Identifies Canine Natural Killer Cell Subsets With Phenotypic Similarity to Human Natural Killer Cells. Front Immunol (2016) 7:521. doi: 10.3389/fimmu.2016.00521

28. Park JY, Shin DJ, Lee SH, Lee JJ, Suh GH, Cho D, et al. The Anti-Canine Distemper Virus Activities of Ex Vivo-Expanded Canine Natural Killer Cells. Vet Microbiol (2015) 176(3-4):239-49. doi: 10.1016/j.vetmic.2015.01.021

29. Canter RJ, Grossenbacher SK, Foltz JA, Sturgill IR, Park JS, Luna JI, et al. Radiotherapy Enhances Natural Killer Cell Cytotoxicity and Localization in Pre-Clinical Canine Sarcomas and First-in-Dog Clinical Trial. J Immunother Cancer (2017) 5(1):98. doi: 10.1186/s40425-017-0305-7

30. Lee SH, Shin DJ, Kim Y, Kim CJ, Lee JJ, Yoon MS, et al. Comparison of Phenotypic and Functional Characteristics Between Canine Non-B, Non-T Natural Killer Lymphocytes and CD3(+)CD5(dim)CD21(-) Cytotoxic Large Granular Lymphocytes. Front Immunol (2018) 9:841. doi: 10.3389/ fimmu.2018.00841

31. Kim Y, Lee SH, Kim CJ, Lee JJ, Yu D, Ahn S, et al. Canine Non-B, Non-T NK Lymphocytes Have a Potential Antibody-Dependent Cellular Cytotoxicity Function Against Antibody-Coated Tumor Cells. BMC Vet Res (2019) 15 (1):339. doi: 10.1186/s12917-019-2068-5

32. Mizuno T, Kato Y, Kaneko MK, Sakai Y, Shiga T, Kato M, et al. Generation of a Canine Anti-Canine CD20 Antibody for Canine Lymphoma Treatment. Sci Rep (2020) 10(1):11476. doi: 10.1038/s41598-020-68470-9

33. Snyder KM, McAloney CA, Montel JS, Modiano JF, Walcheck B. Ectodomain Shedding by ADAM17 (a Disintegrin and Metalloproteinase 17) in Canine Neutrophils. Vet Immunol Immunopathol (2021) 231:110162. doi: 10.1016/ j.vetimm.2020.110162

34. Tam YK, Maki G, Miyagawa B, Hennemann B, Tonn T, Klingemann HG. Characterization of Genetically Altered, Interleukin 2-Independent Natural 
Killer Cell Lines Suitable for Adoptive Cellular Immunotherapy. Hum Gene Ther (1999) 10(8):1359-73. doi: 10.1089/10430349950018030

35. Jones WM, Walcheck B, Jutila MA. Generation of a New Gamma Delta T Cell-Specific Monoclonal Antibody (GD3.5). Biochemical Comparisons of GD3.5 Antigen With the Previously Described Workshop Cluster 1 (WC1) Family. J Immunol (1996) 156(10):3772-9.

36. Walcheck B, Leppanen A, Cummings RD, Knibbs RN, Stoolman LM, Alexander SR, et al. The Monoclonal Antibody CHO-131 Binds to a Core 2 O-Glycan Terminated With Sialyl-Lewis X, Which Is a Functional Glycan Ligand for P-Selectin. Blood (2002) 99(11):4063-9. doi: 10.1182/blood-2001$12-0265$

37. Mishra HK, Ma J, Mendez D, Hullsiek R, Pore N, Walcheck B. Blocking ADAM17 Function With a Monoclonal Antibody Improves Sepsis Survival in a Murine Model of Polymicrobial Sepsis. Int J Mol Sci (2020) 21(18):1-20. doi: $10.3390 /$ ijms 21186688

38. Huang YC, Hung SW, Jan TR, Liao KW, Cheng CH, Wang YS, et al. CD5-Low Expression Lymphocytes in Canine Peripheral Blood Show Characteristics of Natural Killer Cells. J Leukoc Biol (2008) 84(6):1501-10. doi: 10.1189/ jlb.0408255

39. Moore PF, Affolter VK, Olivry T, Schrenzel MD. The Use of Immunological Reagents in Defining the Pathogenesis of Canine Skin Diseases Involving Proliferation of Leukocytes. In: KW Kwochka, T Willemse, C von Tscharner, editors. Advances in Veterinary Dermatology. Oxford, UK: Butterworth Heinemann (1998).

40. Jing Y, Ni Z, Wu J, Higgins L, Markowski TW, Kaufman DS, et al. Identification of an ADAM17 Cleavage Region in Human CD16 (FcgammaRIII) and the Engineering of a Non-Cleavable Version of the Receptor in NK Cells. PloS One (2015) 10(3):e0121788. doi: 10.1371/ journal.pone. 0121788

41. Ravetch JV, Perussia B. Alternative Membrane Forms of Fc Gamma RIII (CD16) on Human Natural Killer Cells and Neutrophils. Cell Type-Specific Expression of Two Genes That Differ in Single Nucleotide Substitutions. J Exp Med (1989) 170(2):481-97. doi: 10.1084/jem.170.2.481

42. Selvaraj P, Rosse WF, Silber R, Springer TA. The Major Fc Receptor in Blood has a Phosphatidylinositol Anchor and Is Deficient in Paroxysmal Noctural Hemoglobinuria. Nature (1988) 333:565-7. doi: 10.1038/333565a0

43. Huizinga TW, Kerst M, Nuyens JH, Vlug A, von dem Borne AE, Roos D, et al. Binding Characteristics of Dimeric IgG Subclass Complexes to Human Neutrophils. J Immunol (1989) 142(7):2359-64.

44. Tuohy JL, Lascelles BD, Griffith EH, Fogle JE. Association of Canine Osteosarcoma and Monocyte Phenotype and Chemotactic Function. J Vet Intern Med (2016) 30(4):1167-78. doi: 10.1111/jvim.13983

45. Gibbons N, Goulart MR, Chang YM, Efstathiou K, Purcell R, Wu Y, et al. Phenotypic Heterogeneity of Peripheral Monocytes in Healthy Dogs. Vet Immunol Immunopathol (2017) 190:26-30. doi: 10.1016/j.vetimm.2017.06.007

46. Binyamin L, Alpaugh RK, Hughes TL, Lutz CT, Campbell KS, Weiner LM. Blocking NK Cell Inhibitory Self-Recognition Promotes Antibody-Dependent Cellular Cytotoxicity in a Model of Anti-Lymphoma Therapy. J Immunol (2008) 180(9):6392-401. doi: 10.4049/jimmunol.180.9.6392

47. Patel KR, Roberts JT, Barb AW. Multiple Variables at the Leukocyte Cell Surface Impact Fc Gamma Receptor-Dependent Mechanisms. Front Immunol (2019) 10:223. doi: 10.3389/fimmu.2019.00223

48. Lanier LL, Kipps TJ, Phillips JH. Functional Properties of a Unique Subset of Cytotoxic CD3+ T Lymphocytes That Express Fc Receptors for IgG (CD16/ Leu-11 Antigen). J Exp Med (1985) 162(6):2089-106. doi: 10.1084/ jem.162.6.2089

49. Lanier LL, Testi R, Bindl J, Phillips JH. Identity of Leu-19 (CD56) Leukocyte Differentiation Antigen and Neural Cell Adhesion Molecule. J Exp Med (1989) 169(6):2233-8. doi: 10.1084/jem.169.6.2233

50. Lanier LL, Chang C, Phillips JH. Human NKR-P1A. A Disulfide-Linked Homodimer of the C-Type Lectin Superfamily Expressed by a Subset of NK and T Lymphocytes. J Immunol (1994) 153(6):2417-28.

51. Otani I, Niwa T, Tajima M, Ishikawa A, Watanabe T, Tsumagari S, et al. CD56 Is Expressed Exclusively on CD3+ T Lymphocytes in Canine Peripheral Blood. J Vet Med Sci (2002) 64(5):441-4. doi: 10.1292/jvms.64.441

52. Grondahl-Rosado C, Bonsdorff TB, Brun-Hansen HC, Storset AK. NCR1+ Cells in Dogs Show Phenotypic Characteristics of Natural Killer Cells. Vet Res Commun (2015) 39(1):19-30. doi: 10.1007/s11259-014-9624-z
53. Graves SS, Gyurkocza B, Stone DM, Parker MH, Abrams K, Jochum C, et al. Development and Characterization of a Canine-Specific Anti-CD94 (KLRD1) Monoclonal Antibody. Vet Immunol Immunopathol (2019) 211:10-8. doi: 10.1016/j.vetimm.2019.03.005

54. Groh V, Porcelli S, Fabbi M, Lanier LL, Picker LJ, Anderson T, et al. Human Lymphocytes Bearing T Cell Receptor Gamma/Delta Are Phenotypically Diverse and Evenly Distributed Throughout the Lymphoid System. J Exp Med (1989) 169(4):1277-94. doi: 10.1084/jem.169.4.1277

55. Bjorkstrom NK, Gonzalez VD, Malmberg KJ, Falconer K, Alaeus A, Nowak G, et al. Elevated Numbers of Fc Gamma RIIIA+ (CD16+) Effector CD8 T Cells With NK Cell-Like Function in Chronic Hepatitis C Virus Infection. J Immunol (2008) 181(6):4219-28. doi: 10.4049/ jimmunol.181.6.4219

56. Romee R, Foley B, Lenvik T, Wang Y, Zhang B, Ankarlo D, et al. NK Cell CD16 Surface Expression and Function Is Regulated by a Disintegrin and Metalloprotease-17 (ADAM17). Blood (2013) 121(18):3599-608. doi: 10.1182/blood-2012-04-425397

57. Lajoie L, Congy-Jolivet N, Bolzec A, Gouilleux-Gruart V, Sicard E, Sung HC, et al. ADAM17-Mediated Shedding of FcgammaRIIIA on Human NK Cells: Identification of the Cleavage Site and Relationship With Activation. J Immunol (2014) 192(2):741-51. doi: 10.4049/ jimmunol.1301024

58. Mizuno T, Takeda Y, Tsukui T, Igase M. Development of a Cell Line-Based Assay to Measure the Antibody-Dependent Cellular Cytotoxicity of a Canine Therapeutic Antibody. Vet Immunol Immunopathol (2021) 240:110315. doi: 10.1016/j.vetimm.2021.110315

59. Donaghy D, Moore AR. Identification of Canine IgG and Its Subclasses, IgG1, IgG2, IgG3 and IgG4, by Immunofixation and Commercially Available Antisera. Vet Immunol Immunopathol (2020) 221:110014. doi: 10.1016/ j.vetimm.2020.110014

60. Nimmerjahn F, Ravetch JV. Fcgamma Receptors as Regulators of Immune Responses. Nat Rev Immunol (2008) 8(1):34-47. doi: 10.1038/nri2206

61. Grondahl-Rosado C, Boysen P, Johansen GM, Brun-Hansen H, Storset AK. NCR1 Is an Activating Receptor Expressed on a Subset of Canine NK Cells. Vet Immunol Immunopathol (2016) 177:7-15. doi: 10.1016/j.vetimm. 2016.05.001

62. Judge SJ, Yanagisawa M, Sturgill IR, Bateni SB, Gingrich AA, Foltz JA, et al. Blood and Tissue Biomarker Analysis in Dogs With Osteosarcoma Treated With Palliative Radiation and Intra-Tumoral Autologous Natural Killer Cell Transfer. PloS One (2020) 15(2):e0224775. doi: 10.1371/ journal.pone. 0224775

63. Lanier LL, Yu G, Phillips JH. Co-Association of CD3 Zeta With a Receptor (CD16) for IgG Fc on Human Natural Killer Cells. Nature (1989) 342 (6251):803-5. doi: 10.1038/342803a0

64. Letourneur O, Kennedy IC, Brini AT, Ortaldo JR, O'Shea JJ, Kinet JP. Characterization of the Family of Dimers Associated With Fc Receptors (Fc Epsilon RI and Fc Gamma RIII). J Immunol (1991) 147(8):2652-6.

65. Blazquez-Moreno A, Park S, Im W, Call MJ, Call ME, Reyburn HT. Transmembrane Features Governing Fc Receptor CD16A Assembly With CD16A Signaling Adaptor Molecules. Proc Natl Acad Sci USA (2017) 114(28): E5645-54. doi: 10.1073/pnas.1706483114

66. Gauthier M, Laroye C, Bensoussan D, Boura C, Decot V. Natural Killer Cells and Monoclonal Antibodies: Two Partners for Successful Antibody Dependent Cytotoxicity Against Tumor Cells. Crit Rev Oncol Hematol (2021) 160:103261. doi: 10.1016/j.critrevonc.2021.103261

67. Felices M, Chu S, Kodal B, Bendzick L, Ryan C, Lenvik AJ, et al. IL-15 SuperAgonist (ALT-803) Enhances Natural Killer (NK) Cell Function Against Ovarian Cancer. Gynecol Oncol (2017) 145(3):453-61. doi: 10.1016/ j.ygyno.2017.02.028

68. Vitale M, Cantoni C, Pietra G, Mingari MC, Moretta L. Effect of Tumor Cells and Tumor Microenvironment on NK-Cell Function. Eur J Immunol (2014) 44(6):1582-92. doi: 10.1002/eji.201344272

69. Zahavi D, AlDeghaither D, O'Connell A, Weiner LM. Enhancing AntibodyDependent Cell-Mediated Cytotoxicity: A Strategy for Improving AntibodyBased Immunotherapy. Antibody Ther (2018) 1(1):7-12. doi: 10.1093/abt/ tby002

70. Klingemann H. Immunotherapy for Dogs: Still Running Behind Humans. Front Immunol (2021) 12:665784. doi: 10.3389/fimmu.2021.665784 
71. Zidovetzki R, Rost B, Armstrong DL, Pecht I. Transmembrane Domains in the Functions of Fc Receptors. Biophys Chem (2003) 100(1-3):555-75. doi: 10.1016/s0301-4622(02)00306-x

Conflict of Interest: The authors declare that the research was conducted in the absence of any commercial or financial relationships that could be construed as a potential conflict of interest.

Publisher's Note: All claims expressed in this article are solely those of the authors and do not necessarily represent those of their affiliated organizations, or those of the publisher, the editors and the reviewers. Any product that may be evaluated in this article, or claim that may be made by its manufacturer, is not guaranteed or endorsed by the publisher.

Copyright (๑) 2022 Hullsiek, Li, Snyder, Wang, Di, Borgatti, Lee, Moore, Zhu, Fattori, Modiano, Wu and Walcheck. This is an open-access article distributed under the terms of the Creative Commons Attribution License (CC BY). The use, distribution or reproduction in other forums is permitted, provided the original author(s) and the copyright owner(s) are credited and that the original publication in this journal is cited, in accordance with accepted academic practice. No use, distribution or reproduction is permitted which does not comply with these terms. 